\title{
CARACTERÍSTICAS ANTROPOMÉTRICAS E DESEMPENHO FÍSICO DE SOLDADOS INTEGRANTES DA TROPA DE CHOQUE
}

\section{Anthropometric and physical performance of riot control soldiers}

\author{
Antonio Carlos Contessa Ferreira Junior ${ }^{1}$, Júlia Dubois Moreira ${ }^{1}$; Marcelo Coertjens ${ }^{1,2}$; Luiz Fernando Martins Kruel ${ }^{1}$ \\ ${ }^{1}$ Universidade Federal do Rio Grande do Sul. Escola de Educação Física. \\ Grupo de Pesquisa em Atividades Aquáticas e Terrestres. Porto Alegre, RS, Brasil. \\ ${ }^{2}$ Universidade Federal do Piauí. Campus de Parnaíba. Curso de Fisioterapia. Parnaíba, PI, Brasil.
}

\begin{abstract}
Resumo: A ação da Tropa de Choque caracteriza-se pela rapidez na dispersão do grupamento através da força e potência muscular, entretanto sua preparação caracteriza-se pela especificidade aeróbica. O objetivo deste trabalho foi analisar características antropométricas, força muscular e desempenho físico aeróbico e anaeróbico avaliados em soldados da Tropa de Choque do Exército com resultados da literatura obtidos com atletas do futebol americano, rúgbi e cabo de guerra. Foram avaliados 24 soldados quanto às características antropométricas, potência anaeróbica (Teste de Wingate e salto vertical), força de preensão manual, força de membros superiores no supino e membros inferiores no agachamento através de uma Repetição Máxima (1RM) e Teste de corrida de 12 min e força muscular localizada obtidos no Teste de Aptidão Física (TAF). Os valores médios das características antropométricas foram: estatura $(178 \pm 5 \mathrm{~cm})$, massa corporal total $(79,9 \pm 7,8 \mathrm{~kg})$, massa magra $(68,60 \pm 4,9$ $\mathrm{kg}$ ), percentual de massa gorda $(13,8 \pm 3,6 \%$ ). O pico de potência foi de $773,0 \pm 124,8 \mathrm{~W}$, potência média de $604,5 \pm 69,7 \mathrm{~W}$, trabalho total de $18.136 \pm 2.091 \mathrm{~J}$ e Índice de Fadiga de $58,4 \pm 10,5 \%$. A distância no salto vertical foi de $55 \pm 6 \mathrm{~cm}$. A força de preensão manual foi de $60,8 \pm 15$, $2 \mathrm{kgf}$ (dominante) e 56,2 $\pm 14,7 \mathrm{kgf}$ (não-dominante). No supino foi obtido 75,6 $\pm 20,1 \mathrm{~kg}$ e no agachamento 126,4 $\pm 19,8 \mathrm{~kg}$. Todos os resultados do TAF atingiram os conceitos máximos exigidos. O condicionamento aeróbico e a resistência muscular localizada dos soldados da Tropa de Choque estão de acordo com as exigências do TAF, porém possuem características antropométricas, níveis de força muscular e potência anaeróbica inferiores aos atletas dos esportes analisados.
\end{abstract}

Palavras-chave: Atividades militares, desempenho atlético, exercício, força muscular.

Abstract: The action of riot control soldiers are characterized by rapid dispersion of the group through the muscle strength and power, but their preparation is characterized by specificity aerobics. The objective of this study was to analyze anthropometric characteristics, muscle strength and aerobic and anaerobic exercise performance of riot control soldiers of the Army with the literature results obtained with athletes from football, rugby and tug of war. 24 soldiers were evaluated with regard to anthropometric characteristics, anaerobic power (Wingate Test and vertical jump), handgrip strength, strength of upper and lower limbs in bench press and squat using a repetition maximum (1RM) and 12 min running test and muscular strength obtained in the Physical Fitness Test (PFT). Mean values for anthropometric characteristics: height (178 $\pm 5 \mathrm{~cm})$, total body mass $(79.9 \pm 7.8 \mathrm{~kg})$, lean body mass $(68.60 \pm 4.9 \mathrm{~kg})$, percentage of fat mass $(13.8 \pm 3.6 \%)$. The peak power was $773.0 \pm 124.8 \mathrm{~W}$, average power of $604.5 \pm 69.7 \mathrm{~W}$, total work $18.136 \pm 2.091 \mathrm{~J}$ and fatigue index $58.4 \pm 10.5 \%$. The distance in the vertical jump was $55 \pm 6 \mathrm{~cm}$. The handgrip strength was $60.8 \pm 15.2 \mathrm{~kg}$ (dominant) and $56.2 \pm 14.7 \mathrm{~kg}$ (non-dominant). In the bench press was obtained $75.6 \pm 20.1 \mathrm{~kg}$ and $126.4 \pm 19.8 \mathrm{~kg}$ in squat. All results of the PFT reached the maximum required concepts. The aerobic conditioning and muscular endurance of riot control soldiers are in accordance with the requirements of the PFT, but have anthropometric characteristics, levels of muscle strength and anaerobic power to lower sports athletes analyzed.

Keywords: Military activities, athletic performance, exercise, muscle strength.

Aceito em 10/08/12 - Revista de Educação Física 2013 Abr; 157:3-11. Rio de Janeiro - Brasil

\section{INTRODUÇÃO}

Uma Tropa de Choque tem como principal ação coagir as pessoas a deixar um determinado local, cessar suas ações ou impedir que as mesmas desloquem-se por determinado caminho impedindo sua passagem, travando contato físico com um grande número de pessoas quando necessário( ${ }^{(1)}$. A ação de choque é o último recurso para o controle de um distúrbio civil (turba), mas se for necessária deve ser rápida, organizada e vigorosa ${ }^{(2)}$. Para que haja sucesso em tais operações, o elemento surpresa é fundamental para causar desorganização e confusão no grupo de manifestantes, que em uma situação ideal só perceberiam a presença da tropa no momento em que iniciasse o contato físico entre os grupos ${ }^{(3)}$. A Tropa de Choque deve, portanto, formar um grupo coeso fisicamente, de forma a re- 
presentar uma verdadeira barreira humana.

Ao analisarmos a ação de uma Tropa de Choque podemos observar o envolvimento de gestos explosivos, rápida movimentação para seus deslocamentos e grande força muscular de membros superiores e inferiores no momento do contato físico com um grupo de indivíduos. A tropa, geralmente, com menor número de pessoas, deve sobrepujar a resistência oferecida por um grupo maior, empurrando e golpeando com membros superiores e inferiores e empunhando o material de defesa (escudo) e de ataque (cassetete) $)^{(4)}$. Para sobrepujar a força combinada de mais de um oponente são necessários grandes níveis de força máxima e grande potência muscular para os deslocamentos rápidos. Neste sentido, a tropa necessita estar fisicamente preparada e treinada para suportar o estresse físico exigido durante a ação de choque de forma a produzir o resultado esperado.

Alguns esportes como o futebol americano e o rúgbi possuem características semelhantes aquela observada durante a ação de uma Tropa de Choque no que diz respeito ao emprego de grande força e potência muscular contra um grupo de indivíduos $^{(5-7)}$. Este tipo de característica é observado especialmente nos jogadores das linhas de defesa do futebol americano, que se caracterizam por possuírem grande quantidade de massa magra, força e potência muscular ${ }^{(8)}$. Além disso, a exemplo do que ocorre no esporte Cabo de Guerra ${ }^{(9)}$, a força de preensão manual é, igualmente, importante, pois os soldados da Tropa de Choque precisam empunhar equipamentos de defesa e ataque e utilizá-los com força e potência durante sua ação. A demanda energética tanto para a preparação física como para o empreendimento de todas as atividades citadas são semelhantes, exigindo um rápido fornecimento energético para a execução de esforços físicos de grande intensidade e curta duração. Apesar de não ser caracterizado como um esporte, a ação da Tropa de Choque exige, desta forma, uma preparação física adequada e que proporcione condições aos soldados desempenharem suas funções.

Desde o término do último governo militar, a função de Tropa de Choque, originalmente desempenhada pelas Forças Armadas, passou a ser atribuição da Polícia Militar ${ }^{(10)}$. Com o advento da
Constituição Federal de 1988, ficou determinado que em situações de grave perturbação da ordem pública, caso as tropas da Polícia Militar não conseguissem resolver a situação, então, subsidiariamente, seriam acionadas tropas do Exército ${ }^{(11)}$.

O Exército Brasileiro possui tropas com diferentes especialidades, mas a preparação física segue um padrão para todas, dando ênfase à capacidade aeróbica e à resistência muscular localizada que são avaliadas pelo Teste de Aptidão Física $(\mathrm{TAF})^{12)}$. Neste sentido, dadas às características, predominantemente, anaeróbicas das operações de controle de distúrbios civis, este tipo de avaliação física nos parece insuficiente para descrever e avaliar adequadamente a aptidão física da Tropa de Choque para o exercício de suas atribuições. Com exceção dos trabalhos destinados ao estudo de esportes que apresentam características anaeróbicas como os citados acima, não existe na literatura conhecimento relativo à preparação física ou avaliação fisiológica de indivíduos que se dedicam especificamente a ação de choque e controle de distúrbios civis. Apesar de ocorrerem distúrbios em vários países do mundo, provavelmente, o Brasil seja um dos poucos países do mundo a possuir tropas no Exército especializadas neste tipo de operação. Neste sentido, o objetivo deste trabalho foi comparar características antropométricas, força muscular e desempenho físico aeróbico e anaeróbico avaliados em soldados da Tropa de Choque do $3^{\circ}$ Batalhão de Polícia do Exército com resultados da literatura obtidos de atletas do futebol americano, rúgbi e cabo de guerra.

\section{METODOLOGIA}

Participaram deste estudo 24 soldados da Tropa de Choque do $3^{\circ}$ Batalhão de Polícia do Exército de Porto Alegre. Todos os soldados avaliados eram considerados experientes sob o aspecto tempo de serviço (4,5 \pm 1,5 anos), pois para o padrão do Exército Brasileiro os soldados podem servir, no máximo, por seis anos. Além disso, todos os militares da amostra possuíam experiência em missão de paz no exterior, como apoio do Brasil à Organização das Nações Unidas (ONU), em Timor Leste. Foram utilizados apenas soldados, porque os indi- 
víduos com este tipo de função permanecem por todo o seu tempo de serviço militar executando as mesmas atribuições, sendo especializados para uma função apenas. A quantidade de indivíduos foi determinada por ser o número de soldados integrantes de um pelotão de choque do Exército Brasileiro. O pelotão é a célula básica para uma ação de choque e para fins operacionais é indivisível ${ }^{(13)}$. Todos os participantes eram voluntários, foram esclarecidos previamente a respeito dos objetivos e procedimentos deste estudo e assinaram Termo de Consentimento Livre e Esclarecido aprovado pelo Comitê de Ética local, conforme a resolução 196/96 do Conselho Nacional de Saúde.

A coleta dos dados foi realizada para todos os indivíduos desta pesquisa em três dias na seguinte ordem: no primeiro dia foram realizadas as coletas de estatura, massa corporal, dobras cutâneas e o TAF para a predição da capacidade aeróbica e resistência muscular localizada. No segundo dia, foram realizados o teste de salto vertical e o Teste de 30 segundos de Wingate e no terceiro dia foram realizados os testes de preensão manual isométrica e uma Repetição Máxima (1RM) avaliado para o movimento de supino e 1RM estimada para o agachamento a $90^{\circ}$. Todas as coletas foram realizadas com intervalos de sete dias entre cada dia de avaliação.

A estatura e a massa corporal total foram avaliadas através de um estadiômetro e de uma balança digital (Filizola). A composição corporal foi predita através da avaliação de dobras cutâneas por um plicômetro (Cescorf). A massa corporal magra e os percentuais de massa gorda foram preditos utilizando o protocolo de sete dobras cutâneas (tríceps, supra-ilíaca, abdômen, axilar média, peitoral, subescapular e coxa) propostos por Jackson \& Pollock ${ }^{(14)}$, utilizada para o futebol americano ${ }^{(15)}$, para o Cabo de Guerra e o rúgbi(9).

A força de preensão manual isométrica foi avaliada utilizando-se um dinamômetro de mão (kgf) ajustado individualmente ao tamanho da mão (JAMAR, Illinois, EUA). Os indivíduos realizaram três tentativas com cada mão (dominante e não dominante), com intervalo de, no mínimo, um minuto entre as tentativas, sendo considerados válidos os maiores valores atingidos. A força para membros foi avaliada utilizando-se 1RM avaliada para membros superiores e estimada para membros inferiores. Os exercícios utilizados foram o Supino para membros superiores e o Agachamento a $90^{\circ}$ para membros inferiores. Para os dois exercícios foram utilizados uma carga teste inicial, calculada a partir de um percentual da massa corporal do indivíduo de acordo o exercício realizado(16). Após a determinação da carga teste os indivíduos realizaram o maior número de repetições possível até o máximo de dez. Foram realizadas até cinco tentativas para que fosse atingida a carga máxima para uma repetição no Supino e uma carga que permitisse entre uma e dez repetições no Agachamento. Para a estimativa da carga de 1RM e das cargas para cada tentativa, foi utilizada a tabela de correção relativa proposta por Lombardi $^{(17)}$. As fases concêntrica e excêntrica da execução dos movimentos duravam dois segundos. O intervalo aplicado entre as tentativas foi de cinco minutos ${ }^{(18)}$. Os testes de 1RM foram executados com pesos livres utilizando barras e anilhas (Bitello).

A potência anaeróbica alática de membros inferiores foi avaliada pelo teste de salto vertical, para o qual foi utilizada uma plataforma com placa de contato para medir o deslocamento vertical $(\mathrm{cm})$. O movimento de salto foi realizado com a técnica de contramovimento. O deslocamento vertical tem sido utilizado para a predição de desempenho de jogadores de futebol americano ${ }^{(7)}$. Para a realização deste teste, o movimento dos braços foi utilizado livremente e o movimento de membros inferiores na forma de salto contra movimento (SCM) ${ }^{(19)}$. Antes desta avaliação os sujeitos foram familiarizados com a execução do teste.

A potência anaeróbica lática de membros inferiores foi avaliada pelo Teste de Wingate. Este teste caracteriza-se por exigir do avaliado a execução de um esforço físico em intensidade máxima contra uma resistência fixa na maior cadência possível durante 30 segundos em um cicloergômetro (Cybex, EUA). A carga do teste foi determinada como sendo o produto entre a massa corporal e 0,075 kp*kg-1. A resistência no cicloergômetro utilizado foi de frenagem mecânica e tanto a cadência de pedalada (rev*min-1) como a frenagem foram monitorados eletronicamente. Uma calibração manual com car- 
ga conhecida (dois $\mathrm{kg}$ ) foi realizada de acordo com especificações do fabricante no início das coletas de dados. Além disso, calibrações automáticas sempre antecederam a realização de cada teste. Este teste possibilita, também, avaliação da potência anaeróbica alática de membros inferiores.

O TAF constituiu-se dos seguintes testes: Teste de corrida de 12 min de Cooper, flexões e extensões na barra fixa (barra), flexões e extensões sobre o solo (apoio) e abdominal (remador). Com exceção da corrida, todos os testes do TAF exigem que o militar realize o número máximo de repetições possíveis tendo como carga o peso do próprio corpo(12). No teste de corrida de $12 \mathrm{~min}$, avalia-se a distância máxima que o indivíduo percorreu ao final de 12 min de corrida, com o objetivo de predizer o consumo máximo de oxigênio (VO2máx) através da fórmula: VO2máx (ml*kg-1 $\left.{ }^{*} \mathrm{~min}-1\right)$ = D - 504/45 ( $D$ = Distância percorrida em metros). Os resultados obtidos no TAF foram conceituados de acordo com os critérios utilizados pelo Exército para uma população de 18 a $25 \operatorname{anos}^{(12)}$. No teste de barra fixa, observou-se apenas se o militar atingiu o padrão mínimo de suficiência.

Os dados coletados foram analisados através da estatística descritiva (média e desvio padrão) e teste de normalidade Kolmogorov-Smirnov (Lilliefors). Este teste foi realizado com o objetivo avaliar a distribuição dos dados e verificar a existência de desvios da normalidade e outliers nas variáveis do grupo de soldados. Para a análise estatística foi utilizado pacote estatístico SPSS versão 11.0.

\section{RESULTADOS}

A estatura média avaliada dos soldados foi de $178 \pm 5 \mathrm{~cm}$, a massa corporal total foi de 79,9 $9 \pm 7,8$ $\mathrm{kg}$, a massa corporal magra $68,6 \pm 4,9 \mathrm{~kg}$ e a massa corporal gorda de $13,8 \pm 3,6 \%$. A idade média dos soldados avaliados foi de $23,5 \pm 1,5$ anos.

Os valores médios do resultado do TAF foram: $3150 \pm$ 195,6 m no Teste de Corrida de 12 min; 62 execuções no abdominal; 42,6 \pm 13,9 execuções no apoio solo e 11,45 $\pm 2,9$ execuções na barra fixa. $O$ $\mathrm{VO}_{2 m a ́ x}$ predito pelo Teste de corrida de $12 \mathrm{~min}$ foi de 58,7 $\pm 4,7 \mathrm{ml}^{*} \mathrm{~kg}-1^{*}$ min- 1 .

A avaliação de força dos militares apresentou os seguintes resultados para supino $75,6 \pm 20,1 \mathrm{~kg}$, agachamento $126,4 \pm 19,8 \mathrm{~kg}$, força de preensão manual da mão dominante $60,8 \pm 15,2$ kgf e da mão não-dominante 56, $2 \pm 14,7$ kgf.

Em relação aos testes de potência anaeróbica de membros inferiores, os militares atingiram a média de $55 \pm 6 \mathrm{~cm}$ na máxima altura atingida no salto vertical. No Teste de Wingate, os soldados atingiram as médias de pico de potência $773 \pm 124,8 \mathrm{~W}$, de potência média $604,5 \pm 69,7 \mathrm{~W}$, de trabalho total $18.136 \mathrm{~J}$ e de índice de fadiga 58,4 \pm 10,5 \%.

Todas as variáveis avaliadas apresentaram distribuição normal $(p>0,05)$. Isso significa que a maior parte dos soldados apresentou características antropométricas e de desempenho físico em torno da média do grupo. Ou seja, nenhum integrante avaliado possuía desvios significativos em relação à média, nem desvios a normalidade. Não foram encontrados dados tipo outliers.

\section{DISCUSSÃO}

Através da análise dos resultados do TAF, verificamos que os militares da amostra atingiram em média conceito máximo em todos os testes realizados e são considerados aptos fisicamente para o cumprimento de suas atribuições, de acordo com os critérios exigidos pelo TAF referente a indivíduos com idades de 18 a 25 anos $^{(12)}$. Apesar da tendência do Teste de corrida de 12 min superestimar seus resultados, os valores preditos de $\mathrm{VO}_{2 m a ́ x}$ foram maiores do que aqueles encontrados em atletas de futebol americano $43 \pm 5,5 \mathrm{ml}{ }^{*} \mathrm{~kg}-1^{*} \mathrm{~min}-1$ (20) e rúgbi $51,1 \pm 1,4 \mathrm{~m}{ }^{*} \mathrm{~kg}-1^{*} \mathrm{~min}-1^{(9)}$. Jogadores de futebol americano, especialmente os de linha de defesa, possuem médias mais baixas de $\mathrm{VO}_{2 \text { máx }}$ medido diretamente do que atletas de outros esportes, por exemplo, corredores ${ }^{(21)}$. Além desses atletas possuírem um maior percentual de gordura corporal, treinam muito menos o sistema aeróbico em comparação com as valências anaeróbicas. No rúgbi, a via aeróbica é mais exigida do que no futebol americano e as médias de $\mathrm{VO}_{2 \text { máx }}\left(54-60 \mathrm{ml}^{*} \mathrm{~kg}-1^{*} \mathrm{~min}-1\right)$ são semelhantes de outros esportes com predominância anaeróbica como futebol de campo 
(59- $\left.63 \mathrm{ml}^{*} \mathrm{~kg}-1^{*} \mathrm{~min}-1\right)$ e maiores do que as de jogadores de futebol americano ${ }^{(8)}$.

Podemos verificar que a Tropa de Choque está bem condicionada aerobicamente para suas funções, pois possui médias de $\mathrm{VO}_{2 m a ́ x}$ semelhante a esportes com exigências aeróbicas e mais altas do que as médias do rúgbi e do futebol americano, especialmente, em relação aos jogadores de linha defesa. Pincivero e Bompa $^{(8)}$ sugerem que é interessante desenvolver uma boa capacidade aeróbica para os jogadores de futebol americano, pois desta maneira a recuperação dos esforços anaeróbicos seria potencializada. No entanto, apesar desses indivíduos estarem bem condicionados de acordo com os critérios do TAF, não foram encontrados resultados semelhantes no que se refere às características antropométricas e aos testes físicos específicos ao desempenho que devem realizar durante situação de distúrbio de rua, tais como, potência anaeróbica e força muscular, tomando-se como parâmetro atletas de esportes como futebol americano e rúgbi.

Diversos estudos têm sido realizados com jogadores de futebol americano, entre estes Pincivero e $\mathrm{Bompa}^{(8)}$ revisaram extensa literatura sobre o assunto e constataram que eles caracterizam-se por possuírem grande massa magra, muita força e potência muscular, agilidade e velocidade. Nicholas ${ }^{(6)}$ afirma que para o rúgbi as mesmas características são necessárias. Em ambos os esportes há os jogadores das linhas de defesa, que são os responsáveis por impedir a progressão dos adversários e por avançar contra eles chocando-se com os mesmos, semelhante ao que ocorre com a Tropa de Choque quando em contato com a turba. É vantajoso para executar ações que exigem contato físico, possuir grandes quantidades de massa corporal total e de massa magra. Estas características oferecem dificuldade para o oponente, que tem que vencer uma grande resistência representada pela massa corporal total e pela força proveniente da massa muscular. Este tipo de jogador em vários estudos demonstrou possuir médias mais altas de massa corporal total, massa magra, massa gorda, de força máxima de membros inferiores e superiores, além de serem mais altos do que os jogadores de outras funções. Suas médias de $\mathrm{VO}_{2 m a ́ x}$, entretanto, são menores ${ }^{(5 ; 20 ; 22 ; 23)}$.

Podemos observar que as médias de massa corporal total e de massa magra dos militares $(79,9 \pm 7,8 \mathrm{~kg}$ e $68,6 \pm 4,9 \mathrm{~kg}$, respectivamente) foram bem menores do que as médias das mesmas variáveis nos estudos citados (TABELA 1). Esta tendência se confirmou mesmo quando se tratavam de atletas de nível universitário(22,24-26), semelhante a idade dos soldados que incorporam no Exército e que, provavelmente, iriam desenvolver mais massa corporal e massa magra, seja em função da idade ou em função do treinamento ${ }^{(27)}$.

TABELA 1. Média e desvio-padrão das características antropométricas dos soldados da Tropa de Choque e de atletas de futebol americano e rúgbi obtidos a partir da literatura.

\begin{tabular}{lcccc}
\hline Dados da Literatura & Estatura $(\mathrm{cm})$ & $\begin{array}{c}\text { Massa corporal } \\
\text { total }(\mathrm{kg})\end{array}$ & $\begin{array}{c}\text { Massa magra } \\
(\mathrm{kg})\end{array}$ & Massa gorda (\%) \\
\hline Davis et al. ${ }^{(7) *}$ & 187 & 103,5 & - & 10,9 \\
Warrington et al. ${ }^{(9) * *}$ & $188,2 \pm 1,6$ & $104,4 \pm 1,8$ & $86,2 \pm 1,2$ & $16,3 \pm 1,1$ \\
Williford et al. ${ }^{(22) *}$ & $180,9 \pm 2,5$ & $96 \pm 4,6$ & $81,1 \pm 8,1$ & $15,1 \pm 4,6$ \\
Molacek et al. ${ }^{(24)^{*}}$ & $184,2 \pm 5,7$ & $99 \pm 13,4$ & - & $14,6 \pm 7,4$ \\
Hetzler et al. ${ }^{(25)^{*}}$ & $182,3 \pm 7,3$ & $102,3 \pm 21,1$ & - & $13,9 \pm 6,7$ \\
Hoffman et al. ${ }^{(26)_{*}}$ & $179,7 \pm 6,3$ & $93,7 \pm 17,1$ & - & $17,5 \pm 5,3$ \\
Estudo atual & $178 \pm 5$ & $79,9 \pm 7,8$ & $68,6 \pm 4,9$ & $13,8 \pm 3,6$ \\
\hline
\end{tabular}

* atletas universitários de futebol americano; ** atletas de rúgbi

No que se refere à força muscular, Williford et al. ${ }^{(22)}$ mostraram médias de $1 \mathrm{RM}$ de supino $\mathrm{e}$ agachamento de $141 \pm 35,5 \mathrm{~kg}$ e $190 \pm 31,9$ $\mathrm{kg}$, respectivamente em jogadores de futebol americano. Black e Roundy(28) apresentam médias de $1 \mathrm{RM}$ no supino de $167 \pm 23,2 \mathrm{~kg}$ e no agachamento de $231 \pm 8,1 \mathrm{~kg}$, em estudo com jogadores universitários de futebol americano de linha de defesa. Hoffman et al. ${ }^{(26)}$ constataram que ao final de cinco anos o treinamento físico de jogadores universitários de futebol americano proporcionou um aumento médio de $1 \mathrm{RM}$ no Supino de 117,4 $\pm 21 \mathrm{~kg}$ para $153,8 \pm 21,2 \mathrm{~kg}$ e no Agachamento de 152,5 \pm 
$27,3 \mathrm{~kg}$ para $207,4 \pm 35,1 \mathrm{~kg}$. Neste sentido, as médias dos valores de força máxima dinâmica de membros superiores e inferiores dos militares são visivelmente mais baixas do que as médias dos jogadores universitário de futebol americano, principalmente, dos jogadores de linha de defesa, que se caracterizam por serem muito fortes, altos e pesados (TABELA 2). $O$ treinamento destes atletas contempla $O$ desenvolvimento de força e massa magra. Além disso, a própria atividade física durante uma partida exige do jogador o emprego de muita força, contribuindo para o seu aprimoramento ${ }^{(29)}$. No caso dos soldados da Tropa de Choque, seu treinamento físico não enfatiza o aumento da força máxima nem o ganho de massa magra. 0 treinamento das ações de choque fica limitado ao desenvolvimento técnico, pois o emprego real desta tropa praticamente não acontece. Este tipo de ação é muito menos freqüente para o Exército Brasileiro do que para as forças policiais. Sendo assim, podemos compreender as menores médias encontradas nos valores de força máxima de membros superiores e inferiores dos soldados com relação aos atletas. Com relação à força de preensão manual Warrington et al. ${ }^{(9)}$ avaliaram jogadores de rúgbi da linha de defesa e atletas de Cabo de Guerra, encontrando médias de 60,7 \pm 13,2 kgf e $62,2 \pm 20,9 \mathrm{kgf}$ para a mão dominante e de 56,8 $\pm 12,5 \mathrm{kgf}$ e 59,1 $\pm 4 \mathrm{kgf}$ para a mão não-dominante, respectivamente. Neste caso, parece haver semelhança entre as médias dos atletas de linha de defesa de rúgbi, de Cabo de Guerra e dos militares avaliados. É importante ressaltar, novamente, que não foram feitos testes estatísticos comparativos entre os grupos. No caso dos atletas de Cabo de Guerra sabemos que, durante suas competições, precisam exercer grande força para segurar a corda e puxar a equipe adversária por uma distância determinada. Os jogadores de rúgbi de linha de defesa têm como função empurrar e agarrar os oponentes, o que lhes exige, também, força manual. No caso da Tropa de Choque, os soldados, ainda que não sejam, freqüentemente, empregados em uma situação de combate real, durante o treinamento passam empunham e sustentam seus materiais básicos de defesa que são o escudo e o cassetete. A essas características do treinamento podemos atribuir, provavelmente, os resultados semelhantes nos testes de força de preensão manual (TABELA 2).

TABELA 2. Média e desvio padrão dos níveis de força de membros superiores, inferiores $(\mathrm{kg})$ e de preensão manual (kgf) dominante (D) e não dominante (ND) de soldados da Tropa de Choque e atletas de Futebol Americano, Rúgbi e Cabo de Guerra obtidos a partir da literatura.

TABELA 2. Média e desvio padrão dos níveis de força de membros superiores, inferiores $(\mathrm{kg})$ e de preensão manual (kgf) dominante (D) e não dominante (ND) de soldados da Tropa de Choque e atletas de Futebol Americano, Rúgbi e Cabo de Guerra obtidos a partir da literatura.

\begin{tabular}{|c|c|c|c|c|}
\hline Dados da Literatura & Supino & Agachamento & Preensão manual D & Preensão manual ND \\
\hline \multicolumn{5}{|l|}{ Warrington et al. $^{(9)}$} \\
\hline rúgbi & & & $60,7 \pm 13,2$ & $56,8 \pm 12,5$ \\
\hline cabo guerra & & & $62,2 \pm 20,9$ & $59,1 \pm 4$ \\
\hline Williford et al. ${ }^{(22) \text { * }}$ & $141 \pm 35,5$ & $190 \pm 31,9$ & & \\
\hline Molacek et al. ${ }^{(24)^{*}}$ & $130 \pm 3,3$ & & & \\
\hline Hetzler et al. ${ }^{(25)^{*}}$ & $141 \pm 26,6$ & & & \\
\hline Hoffman et al. ${ }^{(26)^{*}}$ & $117,4 \pm 21$ & $152,5 \pm 27,3$ & & \\
\hline Black e Roundy ${ }^{(28)}$ * & $167 \pm 23,2$ & $231 \pm 8,13$ & & \\
\hline Estudo Atual & $75,6 \pm 20,1$ & $126,4 \pm 19,8$ & $60,8 \pm 15,2$ & $56,2 \pm 14,7$ \\
\hline
\end{tabular}

* atletas universitários de futebol americano.

A potência anaeróbica foi avaliada pelos testes de salto vertical e de Wingate. Davis et al. ${ }^{(7)}$ apresentam média de $73,9 \mathrm{~cm}$ para o salto vertical de jogadores de futebol americano de todas as funções. Outros estudos, porém, apresentaram para os jogadores de linha de defesa médias menores, tais como $58,7 \pm 10,6 \mathrm{~cm}^{(23)}$ e $53,6 \pm 5,3 \mathrm{~cm}^{(22)}$ sendo, também, menores do que as médias de jogadores de outras funções. As médias dos militares foram semelhantes às dos jogadores de linha de defesa, porém inferiores às médias de jogadores de um time completo. No Teste de Wingate, Bell et al. ${ }^{(30)}$ apresentam valores, obtidos de jogadores de rúgbi de linha de defesa, com média de pico de potência de 1388 W e de potência média de 1144 W. Não foram encontrados na literatura dados sobre trabaIho total e índice de fadiga com jogadores de 
rúgbi ou de futebol americano. Diversos trabalhos sustentam que uma potência elevada é um importante atributo para esportes de contato físico ${ }^{(7 ; 31)}$.

Estes valores são, absolutamente, mais altos do que aqueles obtidos por jogadores de outras funções e estariam associados a grandes volumes de massa corporal e de massa magra. Apesar dos jogadores de linha de defesa do rúgbi e, por analogia, os do futebol americano, possuírem maior pico de potência absoluta do que os jogadores de outras funções, estes apresentam menores valores de pico de potência relativa à massa magra(5) e à massa corporal total ${ }^{(30)}$. Estes resultados, possivelmente, explicam os resultados mais baixos no teste de salto vertical encontrados nos jogadores de defesa. Os valores médios de pico de potência e potência média apresentada pelos jogadores de rúgbi são mais elevados do que as obtidas pelos militares, apesar dos resultados no teste de salto vertical serem semelhantes. Esse aspecto ressalta que a potência de membros inferiores dos militares está baixa, pois os atletas mesmo tendo maior massa corporal total tiveram um desempenho semelhante no salto. A altíssima potência dos atletas compensou a grande diferença de massa corporal total que existe entre eles e os militares e proporcionou desempenho semelhante no salto. Neste sentido, os menores valores apresentados pelos militares no Teste de Wingate podem estar relacionados não apenas a diferenças na especificidade do treinamento, mas, também, aos seus menores valores de massa corporal total e massa magra.

Este trabalho apresentou pela primeira vez a análise de características antropométricas e de desempenho físico de militares integrantes de uma Tropa de Choque do Exército Brasileiro. Baseado na comparação de dados da literatura relativos a estudos feitos em atletas de futebol americano, rúgbi e cabo de guerra verificou-se que esses militares não apresentaram características antropométricas e de desempenho físico adequado para o tipo de atividade que estão destinados a realizar. Nossa principal limitação está na comparação qualitativa dos dados avaliados dos militares com os da literatura, ao invés da realização de coletas em atletas desses respectivos esportes. Essa limitação se justifica, no entanto, em função desses esportes serem ainda incipientes no Brasil. Pretende-se, dessa forma, sugerir a realização de uma seleção mais específica dos militares que irão fazer parte deste tipo de tropa, bem como, orientar adequações na preparação física desses militares.

\section{CONCLUSÃO}

O presente estudo permitiu verificar que os soldados avaliados estão aptos fisicamente em níveis excelentes pelos padrões de exigência do TAF. Entretanto, enquanto a preparação física dos militares está possibilitando bons resultados no condicionamento aeróbico e resistência muscular, não contempla a especificidade das exigências fisiológicas predominantes na ação do choque. Os valores menores de massa corporal total e de massa magra dos sujeitos avaliados é, provavelmente, o resultado de uma inadequada especificidade do treinamento físico que não visa a hipertrofia muscular e aumento da força e potência muscular, ou então, um inadequado processo de seleção dos indivíduos que farão parte do pelotão. Além disso, os critérios utilizados para avaliação do condicionamento físico, neste caso, o TFM, está incompleto na medida em que não contempla a avaliação de valências essenciais para a realização do trabalho da Tropa de Choque. Provavelmente, esses desajustes devem-se a defasagem das técnicas utilizadas pelas Tropas de Choque do país, pois com a falta de emprego em ações reais não foram necessárias atualizações técnicas e adaptações às novas situações de emprego que normatizassem tanto a seleção como a avaliação e a preparação física dos soldados respeitando a especificidade de ação deste tipo de tropa. 


\section{REFERÊNCIAS BIBLIOGRÁFICAS}

1- Brasil. Exército Brasileiro. Diretoria de Ensino e Pesquisa. Manual de Controle de Distúrbios Civis; IP 19-15. Brasília - DF, 1969.

2. Heal S. Multidões, turbas e armas não-letais. Military Review. 2001;3:58-64.

3. São Paulo. Polícia Militar do Estado de São Paulo: Gabinete de Ensino e Instrução. Manual de Controle de Distúrbios Civis; M8-PM. São Paulo - SP, 1989.

4. Abadio RS. O emprego do policiamento montado em operações de controle de distúrbios civis em área urbana. 2004. Monografia (Especialização em Equitação) - Escola de Equitação do Exército, Exército Brasileiro, Rio de Janeiro, 2004.

5. Brewer J, Davis J. Applied physiology of rugby league. Sports Med. 1995;20:129-5.

6. Nicholas CW. Anthropometric and physiological characteristics of Rugby Union Football Players. Sports Med. 1997;23:375-96.

7. Davis DS, Barnette BJ, Kiger JT, Mirasola JJ, Young SM. Physical characteristics that predict functional performance in division I college football players. J Strength Cond Res. 2004;18:115-20.

8. Pincivero DM, Bompa TO. A physiological review of american football. Sports Med. 1997;23:247-60.

9. Warrington G, Ryan C, Murray F, Duffy P, Kirwan JP. Physiological and metabolic characteristics of elite tug of war athletes. Br J Sports Med. 2001;35:396-01.

10. Brasil. Decreto n. 88.777 , de 30 de setembro de 1983. Aprova o regulamento para as policias militares e corpos de bombeiros militares (R-200). Disponível em: <http://www.planalto.gov.br/ccivil_03/decreto/D88777. htm>. Acesso: 5 de jun 2009.

11. Brasil. Constituição Federal da República Federativa do Brasil; Título V, Capítulo II, art. 142. 1988.

12. Brasil. Portaria $n^{\circ} 032-E M E$, de 31 de março de 2008. Aprova a diretriz para o Treinamento Físico Militar do Exército e sua avaliação. Disponível em: <http://www.pm.pb.gov.br/concursos/upload/arquivos/ CFS_4_26_19_08_2011.pdf > . Acesso: 6 de ago 2012.

13. São Paulo. Polícia Militar do Estado de São Paulo. Gabinete de Ensino e Instrução. Manual do Curso de
Especialização para Oficiais em Controle de Distúrbios Civis. São Paulo - SP, 1997.

14. Jackson AS, Pollock ML. Generalized equations for predicting body density of men. Br J Nutr. 1978;40:497504.

15. Roche AF, Heymsfield SB, Lohman TG. Human body composition. Champaign IL: Human Kinetics Publishers; 1996.

16. Baechle TR, Groves BR. Treinamento de força: passos para o sucesso. 2 ed. Porto Alegre: Artmed; 2000.

17. Lombardi VP. Beginning weight training: the safe and effective way. Dubuque: Wm. C. Brown Company Publishers; 1989.

18. Smith S, Montain S, Matlorr R, Zientara G, Jolezs F, Fielding R. Creatine supplementation and age influence muscle metabolism during exercise. J Appl Physiol. 1998;85:1349-56.

19. Sayers SP, Harackiewicz DV, Harmen EA, Frykman PN, Rosenstein MT. Cross-validation of three jump power equations. Med Sci Sports Exerc. 1999;31:572-7.

20. Shields CL, Whitney FE, Zomar VD. Exercise performance of professional football players. Am J Sports Med. 1984;12:455-9.

21. Millet GY, Banfi JC, Kerherve H, Morin JB, Vincent L, Estrade C, et al. Physiological and biological factors associated with a $24 \mathrm{~h}$ treadmill ultra-marathon performance. Scand J Med Sci Sports. 2011;21(1):54-61.

22. Williford HN, Kirkpatrick J, Scharff-Olson M, Blessing DL, Wang NZ. Physical and performance characteristics of successful high school football players. Am J Sports Med. 1994;22:859-62.

23. Carlson BR, Carter JEL, Patterson P, Petti K, Orfanos SM, Noffal GJ. Physique and motor performance characteristics of US national rugby players. J Sports Sci 1994;12:403-12.

24. Molacek ZD, Conley DS, Evetovich TK, Hinnerichs $\mathrm{KR}$. Effects of low and high volume stretching on bench press performance in collegiate football players. J Strength Cond Res. 2010;24(3):711-6.

25. Hetzler RK, Schroeder BL, Wages JJ, Stickley CD, Kimura IF. Anthropometry increases 1 repetition maximum predictive ability of NFL-225 test for Division IA college football players. J Strength Cond Res. 2010;24(6):1429-39.

26. Hoffman JR, Ratamess NA, Kang J. Performance changes during a college playing career in NCAA division III football athletes. J Strength Cond Res. 2011;25(9):2351-7. 
27. Gabbett TJ. Physiological characteristics of junior and senior rugby league players. Br J Sports Med. 2002;36:334-9.

28. Black W, Roundy E. Comparisons of size, strength, speed and power in NCAA division I-A football players. J Strength Cond Res. 1994;8:80-5.

29. Brechue WF, Mayhew JL. Upper-body work capacity and $1 \mathrm{RM}$ prediction are unaltered by increasing muscular strength in college football players. J Strength Cond Res. 2009;23:2477-86.

30. Bell W, Cooper S-M, Cobner, DE, Philips SJ. Anaerobic performance and body composition of international rugby union players. In: Reilly T, Clarys J, Stibbe A. editors. Science and Football II. London: E \& F.N. Spon; 1993. p. 15-20.
31. Hetzler RK, Vogelpmohl RE, Stickley CD, Kuramoto AN, Delaura MR, Kimura IF. Development of a modified Margaria-Kalamen anaerobic power test for american football athletes. J Strength Cond Res. 2010;24(4):978-84.

\section{ENDEREÇO PARA CORRESPONDÊNCIA:}

Universidade Federal do Piauí - Campus de Parnaíba Avenida São Sebastião, 2819 - Reis Velloso - Parnaíba - PI - CEP: $64.202-020$

Fone: +55 (86) 33235444 - Fax: +55 (86) 33235125 e-mail: a.ferreira11@hotmail.com coertjens@hotmail.com 